\title{
La identidad religiosa en el humanismo bíblico español: Pedro de Valencia y la integración judía e islámica*
}

\author{
Jesús M. ${ }^{\text {a Nieto Ibáñez }}{ }^{* *}$ \\ Universidad de León
}

La obra del humanista Pedro de Valencia pertenece al «humanismo biblista». Religión y política son inseparables en este autor. En la España del siglo XVI existía todavía una parte de la población que pensaba en clave judía o bien en clave islámica. La iglesia española del momento estaba haciendo un esfuerzo enorme por integrar dentro del catolicismo tradicional a los conversos de estas dos comunidades. En este conflicto se enmarcan las justificaciones de la identidad religiosa en varios escritos de Pedro de Valencia. El común denominador de los escritos comentados se resume en la idea de la unidad religiosa de judeoconversos y moriscos bajo la autoridad del rey como respuesta a los conflictos de la España de la época.

Palabras clave: Textos humanistas; exégesis bíblica; judeoconversos; moriscos.

Religious identity in Spanish biblical humanism: Pedro de Valencia and the Jewish AND Islamic InTEGRATION.- The work of the humanist Pedro de Valencia belongs to "biblical humanism". Religion and politics are inseparable in the work of this author. In the sixteenth century, a part of the population in Spain still subscribed to Jewish or Islamic thought. The Spanish church was making a huge effort at the time to integrate within the traditional Catholicism converts from these two communities. In this conflict the justifications of religious identity in various writings of Pedro de Valencia can be located. The common denominator of the writings discussed is summarized in the idea of religious

*Este trabajo ha sido realizado dentro del Proyecto de Investigación titulado «Tradición clásica y patrística y exégesis bíblica en el Humanismo (Pedro de Valencia y Lorenzo de Zamora)» (ref. FFI2012-37448-C03-03) financiado por el Ministerio de Economía y Competitividad (MINECO).

*** jesus.nieto@unileon.es 
unity of Conversos and Moriscos under the authority of the king in response to the conflicts in the Spain of the time.

Keywords: Humanist texts; Biblical exegesis; Conversos; Moriscos.

En la España del siglo XVI existía todavía un sustrato significativo de población que pensaba en clave judía o bien en clave islámica. La iglesia española del momento estaba haciendo un esfuerzo enorme por integrar dentro del catolicismo tradicional a los conversos de estas dos comunidades. El Humanismo bíblico de la época contribuirá a esta labor, como testimonia alguno de los escritos de Pedro de Valencia.

Sin duda el más importante de sus escritos en este aspecto es el titulado «Para la declaración de una gran parte de la Estoria Apostólica en los Actos y en la epístola ad Galatas» ${ }^{1}$. En 1607 escribe Pedro de Valencia este comentario bíblico, dedicado a Bernardo de Sandoval y Rojas, primado de España e inquisidor general, con el fin de actualizar en la España del XVII la interpretación de la traducción literal del texto griego de la epístola paulina Ad Galatas. Se trata de algo más que un estudio de exégesis bíblica, pues se quiere aplicar a la política contemporánea la polémica de la Iglesia primitiva sobre la evangelización de los gentiles, en un momento en que el tema de la limpieza de sangre era una preocupación extendida.

La obra de Pedro de Valencia hay que adscribirla a ese movimiento conocido por «humanismo biblista», dado que el biblismo determina su actividad intelectual, no solo en el campo religioso, sino también en el profano. El Dictatum Christianum de Arias Montano, que nuestro autor traducirá del latín al castellano, es el punto de partida de todo su pensamiento religioso.

En este breve trabajo intentaremos fijarnos en alguno de los aspectos que reflejen la influencia y presencia del humanismo cristiano en la obra de Pedro de Valencia en apoyo de una identidad religiosa en el cristianismo hispano de la época, impregnado de elementos islámicos y hebreos.

\footnotetext{
${ }^{1}$ El texto se conserva en la Biblioteca Nacional de España, Ms. 464, ff. 1r-96v, y copia del siglo XVIII, Ms.13011, ff. 179-251.
} 
Antes de comentar los detalles de este y otros textos similares de Pedro de Valencia hay que tener en cuenta, aunque sea brevemente, el contexto. El Humanismo español renacentista es ante todo humanismo cristiano, el concepto de cultura secular es muy posterior. Es indiscutible que para estos autores la Biblia era un libro sagrado e inspirado por Dios y fueron muy pocos los humanistas que concibieron un mundo o un hombre sin Dios. Aunque el hombre era el centro del universo, en la cosmovisión de los humanistas el estudio de la Biblia constituía la pirámide del saber humano. Al conocimiento de la palabra de Dios se encaminaban los studia humanitatis y a ella subordinaban los humanistas el resto de los saberes ${ }^{2}$. Lo peculiar del Humanismo español es que, frente a otros países donde el objeto principal de estudio fueron los autores grecolatinos, en España este movimiento está ligado al problema religioso y centra desde el primer momento su atención al estudio del texto bíblico. De ahí que la enorme riqueza del Humanismo bíblico español del siglo XVI se manifieste principalmente en las dos Políglotas: la Biblia Complutense del Cardenal Cisneros y la Biblia Real de Arias Montano ${ }^{3}$.

Teniendo en cuenta este componente bíblico del Humanismo español, modernidad y religiosidad pueden parecer dos términos antagónicos, pero que no lo han de ser si los analizamos en este contexto humanista, como se ejemplificará en la actitud de Pedro de Valencia ${ }^{4}$. Precisamente, la principal objeción a la modernidad de nuestro humanista es la presencia en sus obras de argumentos teológicos para tratar temas de diversa índole. Sin embargo, el peso de la religiosidad, Dios y la teología no limitan ni ensombrecen la intelectualidad y la racionalidad de de Valencia.

${ }^{2}$ G. Morocho Gayo, «Humanismo y humanistas: el encuentro con Bizancio», en Humanismo y tradición clásica en España y América, ed. J. M. ${ }^{a}$ NiETo IbÁÑEz (León 2001) págs. 11-18: 14.

${ }^{3}$ Un repaso de las diversas corrientes que confluyen en el biblismo español, en especial la influencia de la cábala y el hermetismo en las grandes figuras del XVI, puede leerse en G. Morocho Gayo, «Hermetismo y cábala cristiana en la Corte de Carlos V: Egidio de Viterbo, Dionisio Vázquez, Cipriano de la Huerga», La Ciudad de Dios 213 (2000) págs. 813-854.

4 J. L. SuÁrez, El pensamiento de Pedro de Valencia. Escepticismo y modernidad en el Humanismo español (Badajoz 1997) pág. 180, y G. Morocho GAYo, «El humanismo español en Pedro de Valencia: tres claves de interpretación», en El Humanismo Extremeño I, eds. Marqués de la Encomienda \& alii (Trujillo 1997) págs. 115-142: 117. 
Pedro de Valencia se halló inmerso en un gran número de casos y controversias religiosas, protagonizadas por herejes, conversos, moriscos, brujas, hechiceros, astrólogos judiciarios, visionarios, adivinos, etc. y en ellos su actitud será la de un hombre culto, precursor del pensamiento ilustrado ${ }^{5}$. Todo lo impregna su sentimiento religioso, pues sus tratados de política y economía, o, por ejemplo, las cartas a Alonso Ramírez al ser nombrado fiscal de hacienda, los envíos al rey Felipe III o a la reina Margarita ${ }^{6}$ no son reflexiones teóricas en el campo social, político o económico, sino llamadas de atención a la moralidad con que cada cristiano debe ejercer su oficio y estado.

Lo religioso se funde con lo político, lo social y lo económico. El fin último de la vida en comunidad es el bien público, «la pública utilidad», y para ello es esencial la prudencia y la justicia, es decir, que la riqueza esté bien repartida entre todos los miembros de la comunidad, la República, que llama nuestro autor ${ }^{7}$. El mensaje es de san Pablo, a saber, la caridad y el amor con los demás hombres, tema muy explotado en el Humanismo, en coincidencia con el estoicismo, que hace iguales en condición a todos los seres humanos y presenta a la virtud como el mayor bien y supremo deber del hombre con él mismo y con Dios ${ }^{8}$.

Junto al problema político y social es la inquietud religiosa y de Dios la otra gran preocupación. Sin embargo su concepción política es inseparable de la religiosa, en busca de reforma de las estructuras sociales y económicas que regían la España del momento, pero con un tratamiento

5 L. Gómez Canseco, El humanismo después de 1600: Pedro de Valencia (Sevilla 1991) pág. 174. Pedro de Valencia analizó en su «Discurso acerca de los cuentos de las brujas y cosas tocantes a magia» las distintas supersticiones populares y cultas, como pronósticos astrológicos, plomos de dudosa antiguiedad o cuestiones de brujería. En este último caso critica los métodos de la Inquisición, que carecen a menudo de garantías jurídicas, y rechaza como nulas las declaraciones obtenidas bajos tortura o presión.

${ }^{6}$ Interesantes reflexiones sobre la condición espiritual de la mujer se pueden leer en el escrito dirigido a la reina Margarita, en concreto en el que la elogia por la fundación de un convento de Agustinas Descalzas; cf. Pedro de Valencia. Obras completas. IV. Escritos sociales. 2. Escritos políticos (León 1999) págs. 481 y ss.

7 SuÁrez, El pensamiento, pág. 179.

8 Gómez Canseco, El humanismo, pág. 151. 
respetuoso de la religión católica y del modelo político monárquico, que es incuestionable ${ }^{9}$.

Como ya hemos apuntado, el Dictatum Christianum de Arias Montano, traducido como Lección Cristiana por Pedro de Valencia, abunda en la cuestión de la identidad religiosa de la época, no ya tanto para España, como para toda la cristiandad. Los motivos que impulsaron a Arias Montano a escribir esta obra podrían ser su deseo de contribuir a la pacificación de los Países Bajos, en particular, y de la cristiandad escindida, en general, por medio de un programa de vida simple y basado en la Escritura, que todos pudieran aceptar ${ }^{10}$. Numerosas han sido las interpretaciones de esta obra de Montano, desde la erasmista y familista, hasta la ecuménica ${ }^{11}$. Para M. Andrés ${ }^{12}$ se trata de la primera obra de espiritualidad ecuménica, cuya intención es restaurar la unidad eclesial. El problema básico de la época, tanto en el plano religioso como en el político, era la reunificación de la Iglesia, la unidad de los cristianos, como indica su Prólogo:

Yo a lo menos, por manifiesto tengo que la causa de este castigo que Dios embía son pecados de la república i de todos en general, porque entiendo que casi la mayor parte de los cristianos está, no solo dividida en varias sectas, i engañada i llevada de diversos errores, sino aun hinchada i sobervia con ellos; i la otra parte que profesa la comunión de la fee católica i la verdadera dotrina, veo que la egercita con mucho descuido i casi la pervierte.

En «Para la declaración de una gran parte de la Estoria Apostólica en los Actos y en la epístola ad Galatas ${ }^{13}$ Pedro de Valencia insiste en la

9 El respeto por la forma monárquica contrasta con las críticas a la estructura nobiliaria, lo que supone para Pedro de Valencia ponerse al lado de los burgueses que teorizaron a favor de la unión entre el pueblo y su rey para impedir las desigualdades impuestas por la nobleza. En ocasiones se presenta a los hombres más como ciudadanos de una república que como súbditos de una monarquía; cf. SuÁREZ, El pensamiento, págs. 277-273.

${ }^{10}$ Cf. Introducción de A. MARTín, en Pedro de Valencia. Obras completas IX/2. Escritos espirituales. La Lección cristiana de Arias Montano (León 2002) pág. 105.

${ }^{11}$ Cf. el estudio de J. PARAdinas, en Pedro de Valencia. Obras completas IX/2., págs. 24 y ss.

${ }^{12}$ Benito Arias Montano. Leción Christiana. Dictatum Christianum. Traducción de Pedro de Valencia. Introducción de M. Andrés Martín (Huelva 2003).

13 Seguimos el estudio y la edición de M. ${ }^{a}$ Prado Ortiz Sánchez, Pedro de Valencia. Obras completas. II. Escritos bíblicos y teológicos (León 2014) págs. 297-537. 
idea de que la irrupción del cristianismo supone la llegada de igualdad de derechos para todos ${ }^{14}$, algo que no ocurría en el mundo judío. El apóstol Pablo en la carta Ad Galatas manifiesta su deseo e intención de expandir el evangelio a los gentiles, dado que tanto los gentiles como los judíos son pecadores y que el único camino para la salvación es la fe en Jesucristo, con independencia de la observancia o no de la Ley mosaica. Realmente lo que se pretendía era promover el respeto de los judíos a los gentiles, al margen del cumplimiento o no de esa Ley. Pedro de Valencia, como ya hizo Pablo, deseaba también propiciar la tolerancia y el respeto hacia el distinto, proponiendo la convivencia y coexistencia de cristianos con judíos; entonces se pedía a los judíos que aceptasen la entrada de la gentilidad en la Iglesia, y ahora es al contrario:

Pero para los tiempos dichosos del Nuevo Testamento y la perfecta unidad de la Iglesia en Cristo nuestro Señor, estaba profetizado que no habría esta distinción, sino que los advenas habitationis cesarían del todo, y se acabarían y no se admitirían por ser la Iglesia Católica universal madre de todos los creyentes, fuera de la cual no puede haber salud. Y así el que dejare sus errores habría de hacerse del todo cristiano y verdadero israelita, y no en parte, como los convertidos a la ley de Noé; y los que verdaderamente se convirtiesen al cristianismo, de cualquier nación y profesión de religión que antes fuesen, serían admitidos a igual nombre, honra y provecho, sin distinción ni diferencia como ciudadanos e hijos legítimos, y les cabría suerte y herencia en lo bueno y mejor conforme a su fe y obras virtuosas ${ }^{15}$.

Como ya hemos precisado al comienzo de este artículo, Pedro de Valencia envió al cardenal Rojas y Sandoval este texto en el que, haciendo uso de todos sus conocimientos bíblicos y clásicos, se detiene a estudiar pormenorizadamente el momento histórico en que el cristianismo se abrió a los gentiles, a los no judíos, y se abandonaron las prácticas propias de la

14 La misma idea se adopta en lo social, como es el caso del escrito «Discurso sobre el acrecentamiento de la labor de la tierra», donde se expone la necesidad de una profunda reforma agraria para corregir las desigualdades económicas. En el «Discurso sobre el precio del trigo» su propuesta es que el Estado intervenga para evitar la subida del pan y favorecer así a «la gente ordinaria y popular, que es la mayor parte de la República». Estos textos están editados en Pedro de Valencia. Obras completas IV. Escritos sociales 1. Escritos económicos (León 1994).

15 Pedro de Valencia. Obras completas. II., pág. 382. 
Ley judaica. En el mismo hace referencia a los duros momentos que vivió la Iglesia cristiana en sus comienzos, y no solo por los problemas que traía haber sido una religión perseguida, sino por los asuntos de índole interna que suscitaron algunas disputas y enfrentamientos. Las disensiones que se originaron en su seno venían propiciadas en gran medida por la actitud ante la revelación antigua que propugnaba, fundamentalmente, la religión judía.

El tema principal es el Concilio de Jerusalén y el abandono de las prácticas judaicas en el cristianismo primitivo, con especial atención a las cartas de san Pablo y a los pasajes de los Hechos de los Apóstoles más significativos al respecto. Se critica duramente la interpretación estricta que se había hecho de la Ley en determinados círculos judíos. Pablo, siguiendo a Cristo, opta por la justicia y el amor al prójimo como única y auténtica Ley ${ }^{16}$.

Pero este tema para Pedro de Valencia era algo más que una cuestión teológica. Las cuestiones tratadas tienen un claro reflejo en las polémicas que agitaban el terreno religioso de la España de finales del siglo XVI y principios del XVII. Las contiendas entre la monarquía española y el papado, la rivalidad con otras potencias e iglesias europeas, el auge del protestantismo y la importancia de la figura del apóstol Santiago en el catolicismo español. Sobre todo es lógico pensar que el humanista establece en esta obra un símil entre el panorama eclesiástico que encuentra en una España donde conviven cristianos viejos y recién convertidos con lo que ocurría en la iglesia del siglo $\mathrm{I}^{17}$, con cristianos fuertes en su fe y otros aun portadores de las tradiciones judías. Pedro de Valencia también vuelve los ojos hacia los textos fundacionales del cristianismo, como es especialmente en este caso la Carta a los Gálatas, buscando un respaldo para su propia fe.

${ }^{16}$ Resulta llamativo que Pedro de Valencia acuda a Pablo, el único seguidor de Cristo de procedencia judía, pero con un amplio bagaje cultural griego y romano.

17 Tanto en este tratado, como en el «Tratado acerca de los moriscos», Pedro de Valencia manifiesta la importancia de ser tolerante con el otro. Refiriéndose a los judíos decía que tenían que atender a la fe en Cristo y no al cumplimiento o no de los preceptos de la ley; y en cuanto a los moriscos mantenía que había que ser tolerante con ellos, sin prestar demasiada atención a las cosas pequeñas, sino al grueso, es decir, a lo que atañe a la doctrina. 
Pedro de Valencia siguiendo a Pablo defiende el hecho de que, a pesar del problema de los judaizantes, la Iglesia consigue ser una y universal. Como conclusión presenta a la nueva Iglesia que ofrece a las gentes la libertad. Cristo con su muerte y resurrección ha roto el yugo de la antigua Ley. Con la llegada del cristianismo la circuncisión ha sido superada por la fe y la caridad ${ }^{18}$. Los gentiles ya no son extranjeros, sino conciudadanos $^{19}$. ¿Qué sentido tiene esto en el siglo XVII español? Paz y unidad del reino, este es el objetivo principal. Además del problema de los judeoconversos, es de sobra conocido el de los moriscos, que ocupa otro de los tratados de Pedro de Valencia. Si la extensión de este trabajo nos lo permitiera, habría que analizar la política de conversión de los moriscos a principios del siglo XVII, al menos en lo que a la asimilación religiosa de los moriscos y la necesaria restauración de España se refiere ${ }^{20}$. En 1609 se decreta definitivamente la expulsión de los moriscos por Felipe III, después de haber atendido varios informes al respecto, uno de ellos el escrito de Pedro de Valencia. El humanista muestra una confianza en la integración del moro. La tolerancia religiosa no es un inconveniente para la paz de la república. Sin embargo, aunque social y económicamente los moriscos son un grupo de ciudadanos aptos para la república, en el orden religioso no lo son:

Los derechamente enemigos declarados y manifiestos de toda la cristiana Iglesia y como fatales contrarios en cuanto a encuentro y guerra exterior, son los moros, digo, todos los que profesan y tienen por religión la secta de Mahoma, que son de la familia y casa de Ismael... porque los cristianos todos somos y nos llamamos hijos de Abraham, por la vía de Isaac $^{21}$.

${ }^{18}$ En el Dictatum christianum el tema central es el amor, como eje del cristianismo, a partir del texto paulino de I Cor 13, 4-8.

19 Ef 2, 19.

20 G. MAGnIER, «La visión de Pedro de Valencia de un cristianismo sin divisiones», en VIII Simposio Internacional de Mudejarismo. De múdejares a moriscos: una conversión forzada, II, Centro de Estudios Mudéjares (Teruel 2002) págs. 673-684; Pedro de Valencia, Sobre el pergamino y láminas de Granada (Oxford-New York 2006), y Pedro de Valencia and the Catholic Apologists of the Expulsion of the Morisques (Leiden 2010).

${ }^{21}$ Pedro de Valencia. Obras completas. IV. Escritos sociales. 2., pág. 74. 
De Valencia se opone a las soluciones brutales para este colectivo, como pasarlos a cuchillo, castrarlos, expulsarlos o trasladarlos a Terranova; más bien, propone como medida su dispersión, su conversión paciente a la fe católica y la mezcla absoluta con la población cristiana a través de una política favorable a los matrimonios mixtos para integrarlos y asimilarlos. Los descendientes serán cristianos limpios de toda mancha e integrados en la sociedad cristiana ${ }^{22}$. Pedro de Valencia exhorta al reino a la caridad, a la práctica de una política de asimilación, seguramente imposible de realizar ya:

Conviene pues que, esparcidos los moriscos, se trate de su verdadera conversión con amor y caridad, que vean ellos que los queremos bien ... ${ }^{23}$

Tolerancia, paciencia y amor, como aquí, es lo que se extrae del «Tratado acerca de los moriscos de España» de sus comentarios bíblicos actualizados, en especial de la «Declaración de la Estoria Apostólica». El humanista opta por un cristianismo sin divisiones, donde la renovación espiritual tuviera más peso que las observancias externas. La misma idea es defendida en su crítica «Sobre el pergamino y láminas de Granada», compuesta en 1607. Aparecieron en el Sacromonte granadino unas láminas de plomo, fruto de una falsificación a la que se opusieron siempre los Papas, con ideas como la de que solamente España era el pueblo elegido, sobre la certeza de la venida de Santiago a la Península y el hecho de que sus discípulos estaban sepultados en el Sacromonte y la defensa del misterio de la Inmaculada en sentido docetista. Este acontecimiento, de primera importancia política y religiosa, hay que situarlo dentro del conflicto de las tres religiones. Precisamente es el contexto morisco el que puede explicar estas falsificaciones tanto desde el punto de vista del contenido como de su expresión lingüística ${ }^{24}$. Diversos intelectuales pujaron por un sincretismo entre musulmanes y cristianos, facilitando la

${ }^{22}$ Gómez Canseco, El humanismo, págs. 240 y ss.

23 Pedro de Valencia. Obras completas. IV. Escritos sociales. 2., pág. 123.

${ }^{24}$ M. García-Arenal y F. Rodríguez Mediano (Un Oriente español. Los moriscos y el Sacromonte en tiempos de Contrarreforma [Madrid 2010]) analizan los ambientes moriscos en que se pudieron producir estas láminas y la repercusión que ellos han tenido en el conocimiento y uso de la lengua árabe en España y en su consideración en la propia historiografía hispana. 
integración de los moriscos conversos en detrimento de los judíos en una nación moderna ${ }^{25}$. Era una aberración el hecho de dar como escritos de época apostólica un pergamino y unas láminas de plomo, escritos en árabe, latín y español, el cual ya se hablaba en tiempos de Nerón, afirmar que el catolicismo español había sido divulgado por apóstoles árabes, y que al final de los tiempos serían los árabes los que conseguirían la unidad de la Iglesia y la unidad de todos los pueblos en la verdadera fe, que parecía ser la de Mahoma. Los Apócrifos del Sacromonte, además, hacían una síntesis de la teología escolástica decadente de aquella época y de las doctrinas del Alcorán y libros de teología islámica. Daban como verdades históricas hechos que la crítica contemporánea había demostrado que eran falsos (venida de Santiago a España) o doctrinas que ya habían sido condenadas por la Iglesia antigua (docetismo, nestorianismo, arrianismo, islamismo), todo ello con la finalidad expresa de oponerse «a los judíos y herejes de estos tiempos» ${ }^{26}$. En definitiva, Pedro de Valencia intenta convencer a Felipe III de que los moriscos pueden formar parte de la cristiandad y se poya para ello también en la providencia divina, como lo hacían los apologistas católicos para argumentar su expulsión sirviéndose de diversas visiones y profecías en las que España desempeñaba un papel preeminente en la cristianización ${ }^{27}$.

Como hemos visto, religión y política son inseparables en el autor. En su preocupación por la extensión del cristianismo a los gentiles o a los infieles, nuestro humanista destaca en varios lugares más la misión «divina» de la realeza hispánica y la idea de la expansión de la cristiandad. En su religiosidad hay que tener en cuenta su identificación con la monarquía, con una monarquía católica, cuya función es mantener la unidad de la fe. En su tratado «Descripción de las virtudes» nos encontramos con la

${ }^{25}$ D. Cabanelas Rodríguez, «El Sacromonte, punto de confluencia doctrinal entre el Islam y la Cristiandad», en La Abadía del Sacromonte. Exposición artístico-documental. Estudio sobre su significación y origen (Granada 1974) págs. 34-40, e «Intento de supervivencia en el ocaso de una cultura: Los Libros plúmbeos de Granada», Nueva Revista de Filología Hispánica 30 (1981) págs. 333-358.

26 G. Morocho Gayo, «Los Sarraceni y los Apócrifos de Granada en el tránsito del Humanismo renacentista español al Barroco», en Herencia greco-latina en la lengua y literaturas castellanas, ed. N. Castrillo Benito (Burgos 2000) págs. 163-190: 171.

27 En este aspecto es fundamental la reciente monografía de MAgnier, Pedro de Valencia and the Catholic Apologists, en especial, págs. 49 y ss. 
imagen poderosa del monarca, con la simbolización del poder absoluto del rey como alter ego de Dios en la tierra ${ }^{28}$. Se trata de un programa sobre las virtudes que deben acompañar al príncipe para el buen gobierno de los reinos. De hecho en una de las frases del texto afirma: «Del ejercicio de estas virtudes (las cuatro cardinales y sus respectivas subordinadas) se siguen como frutos dellas en los Reinos y en las repúblicas, Felicidad, Paz, Concordia, Abundancia, Vitoria, Honra, Fama y Eternidad».

En la «Dedicatoria a la reina doña Margarita de su libro intitulado De las enfermedades de los niños» ${ }^{29}$ leemos varias precisiones sobre el origen divino de la Corona, su privilegiada situación como cabeza del estado, sobre el rey como padre de familia y, por ende, la reina como madre, el rey como buen pastor, que recuerda la imagen de Cristo y los cristianos, el rey como el hombre dotado de unas virtudes excepcionales, por encima de las de cualquier ciudadano, con un respeto y temor a Dios, reflexivo, sin interés por el elogio y la fama, humilde, defensor de la cristiandad y, sobre todo, prudente y justo:

... es a la persona de Vuestra Majestad que es en su oficio también. Llamamos ansí al lugar y ministerio en que Dios puso a Vuestra Majestad dándoselo el más alto que mujer puede ocupar en la tierra haciéndola mujer del mayor y más poderoso Rey que tiene ni ha tenido el mundo.

El origen divino de la monarquía hispana y el deber del príncipe de defender la fe cristiana se destaca al final de esta dedicatoria a la reina:

Dios con providencia particular adorna y favorece la línea y propagación de los príncipes de la casa de Austria. Y los que ha ensalzado y engrandecido señaladamente con la sucesión en los reinos de Castilla y con la tierra real, como a familia verdaderamente real y imperial de que saca águilas en cuyas manos pone los rayos y armas de su justicia para que peleen sus batallas en defensa de la Iglesia Católica y la limpieza de la lepra de la herejía y infidelidad y como Davides hechos conforme al

${ }^{28}$ En relación a estos temas en el reinado de Felipe III remitimos a A. Ferós, El Duque de Lerma: realeza y privanza en la España de Felipe III (Madrid 2002).

29 La edición de estos tratados se contiene en Pedro de Valencia. Obras completas. VI. Escritos varios (León 2012). 
corazón de Dios destierran de la ciudad de Dios a todos los perniciosos

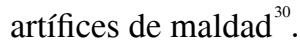

En este escrito dedicado a la reina Margarita la familia real es la imagen del reino, lo que puede ponerse en relación con la idea de una sociedad igualitaria que aparece en la obra de nuestro autor. Hay un deseo de organizar la sociedad de manera que todos los ciudadanos fueran iguales respecto al único poder claramente preponderante, es decir el monarca católico. Pedro de Valencia aspira a conseguir una vida mejor social y económicamente para toda la población española, para cada uno de los ciudadanos que forma la República cristiana. Religión y política van siempre unidas en estos escritos:

Por esto confío también que ganarán más gracia estos escritos con Vuestra Majestad cuya caridad cristiana la hace madre universal de todos sus vasallos para que con afecto y entrañas de amor desee y procure la salud de todos los hijos de sus súbditos, multiplicación y propagación como de ganado propio de Dios y suyo deben procurar mucho los Reyes y es su mayor hacienda y caudal ...

En el escrito «Descripción de la justicia en ocasión de querer Arias Montano comentar las leyes del reino» se tocan los temas habituales en nuestro humanista, en especial el hecho de que los reyes reciben el poder de Dios. Se apoya esta idea con dos citas clásicas, una de Homero ${ }^{32}$ sobre la herencia que Agamenón recibió de su cetro, y la otra de un peán de Píndaro $^{33}$, que llama a Dios, a Zeus de Dodona, el supremo artífice y maestro, A $\rho 1 \sigma \tau o ́ \tau \varepsilon \chi v \alpha \varsigma$, Dodonaee potentissime optimae artis artifex, pater. El rey Felipe III está dotado de las demás virtudes, pero especialmente de la de la justicia.

Para finalizar, como común denominador de los escritos comentados podemos decir que todo se resume en la idea de la unidad religiosa bajo la autoridad del rey como respuesta a los conflictos de la España de la época. No hay monarquía estable sin unidad religiosa. No puede haber

\footnotetext{
30 Pedro de Valencia. Obras completas. VI., págs. 285-286.

31 Pedro de Valencia. Obras completas. VI., pág. 285.

32 Il. II 100-110.

${ }^{33}$ Pi., Fr. 57. Se trata de una invocación al Zeus de Dodona, el más antiguo culto profético griego.
} 
separación entre religión y política, entre lo justo y lo útil en palabras tomadas por nuestro humanista de Sócrates ${ }^{34}$. Pedro de Valencia, un hombre profundamente católico y monárquico, que asiste perturbado al inicio histórico de la modernidad, no puede entender la realidad sin Dios. En el gran tratado de filosofía, Academica, reconoce al final que el mejor camino hacia la verdad es hacerlo a través de Dios, lo que apunta a la religiosidad sincera de nuestro autor. La fe católica es tomada por él como una garantía:

Qui igitur vera sapientia indigere se mecum sentiet, postulet, non ab huismodi philosophia, sed a Deo, quid at omnibus affuenter et non improperat $^{35}$.

Frente a los conflictos y polémicas en los que se vio envuelto Pedro de Valencia, la firme oposición a los partidarios de la autenticidad del pergamino y láminas de Granada, o el informe sobre los excesos cometidos en el auto de fe de Logroño en relación con la represión de la brujería, la Sagrada Escritura constituye la verdadera filosofía y la última razón de los problemas jurídicos y morales. El humanista trata de buscar en la Biblia la verdadera solución a todos los problemas de su tiempo, sobre todo con el espíritu de la caridad y tolerancia con el que Pablo quiso evangelizar a los gentiles.

Recibido: 25/3/2014

Aceptado: 06/07/2015

34 J. M. ${ }^{a}$ Nieto IbÁÑ̃̃z, «Sócrates en los escritos de Pedro de Valencia: justicia,

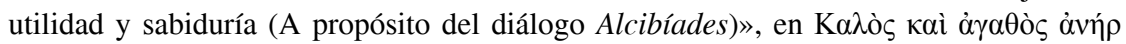
$\delta 1 \delta \alpha \sigma \kappa \alpha ́ \lambda o v ~ \pi \alpha \rho \alpha ́ \delta \varepsilon \imath \gamma \mu \alpha$. Homenaje al Profesor Juan Antonio López Férez, eds. L. M. Pino y G. Santana (Madrid 2013) págs. 587-592: 588.

35 Pedro de Valencia. Obras completas III. Academica (León 2006) pág. 244. 